\title{
Elemento subjetivo del delito: una lectura escéptica desde Kant
}

\author{
Subjective Element of Crime: \\ A Skeptic Reading from Kant
}

\author{
Diego Pérez Lasserre* \\ *Pontificia Universidad Católica de Chile \\ dperez1@uc.cl \\ http://dx.doi.org/10.22235/rd.v1i15.1380
}

ReSUmen: El presente artículo pretende revisar la discusión propia del Derecho Penal entre los causalistas y finalistas a partir del análisis de la libertad que Kant hace en la tercera antinomia de su Crítica de la Razón Pura, a fin de sacar a la luz el tema de fondo que subyace en dicha discusión y revisar la atingencia o no del mismo.

Palabras Clave: derecho penal, causalistas y finalistas, Kant, libertad.

ABSTRACT: The present article intends to review the discussion between causalists and finalists in Criminal Law from the analysis of the freedom that Kant makes in the third antinomy of his Critique of Pure Reason, in order to bring to light the underlying theme in this discussion and to review its attainment.

KeYwords: criminal law, causalistas and finalists, Kant, freedom.

Sumarıo: I- La libertad en la crítica de la Razón Pura. II- Causalidad y culpabilidad: el caso del derecho penal. III- Límites De Lo Cognoscible Mediante La Razón Especulativa: Un Insumo Útil Para La Culpabilidad. IV- Conclusiones. V- Bibliografía. 
El hombre es, pues, Fenómeno, por una parte, y, por otra, esto es, en relación con ciertas facultades, objeto meramente inteligible ${ }^{1}$. Immanuel Kant

El tratamiento que Kant da a la libertad a lo largo de sus obras es un asunto de suma complejidad. De hecho, y como bien señala Allison, hay incluso autores que dan cuenta de que es posible distinguir cinco conceptos distintos para este fenómeno ${ }^{2}$ en la obra kantiana ${ }^{3}$. No sorprende, sin embargo, que el filósofo de Königsberg se haya dedicado largamente a reflexionar sobre este asunto, ya que la libertad, entendida ésta en su sentido trascendental, es decir, como "absoluta espontaneidad causal que inicie por si misma una serie de fenómenos que se desarrollen según leyes de la naturaleza” (A 446, B 474), resulta bastante problemática en el sistema kantiano. En efecto, el hablar de la libertad como independiente de la causalidad patológicamente ${ }^{4}$ determinada equivale a decir que, para que una acción se estime como libre, ésta ha de ser considerada como un acontecimiento temporal del cual es correcto negar que toda determinación causal-patológica se le aplica 5 .

Ahora, si bien la dificultosa tarea de concebir (e incluso probar, en algunos casos) la posibilidad de la coexistencia entre una causalidad por naturaleza y una causalidad por libertad ha sido discutida primordialmente en sede filosófica, ésta no ha sido la única rama del saber que se ha visto cautivada por dicha disquisición. Disciplinas como la física y el derecho también se han dedicado largamente a estudiar esta materia, llegando incluso la

\footnotetext{
(A 547, B575). En el presente trabajo se ha utilizado la traducción de Pedro Ribas de la Crítica de la Razón Pura: Immanuel Kant, Crítica de la Razón Pura, trad. Pedro Ribas (México D.F., Taurus, 2013).

2 Palabra tomada en su sentido coloquial, no en el sentido técnico kantiano

3 Cf. Henry E Allison, Idealism and Freedom: Essays on Kant's Theoretical and Practical Philosophy (Cambridge; New York: Cambridge University Press, 1996), 129.

4 Kant entiende lo patológico como lo sensiblemente condicionado.

5 Cf. William L Harper y Ralf Meerbote, Kant on Causality, Freedom, and Objectivity (Minneapolis: University of Minnesota Press, 1984), 145.
} 
primera de ellas a descubrir que el principio de causalidad se ve alterado nivel subatómico. En la segunda de las disciplinas enunciadas [el derecho], "el problema de la libertad de la voluntad y sus repercusiones en la valuación de la conducta humana, cuestión cuyo origen la enclava en la metafísica y la filosofía moral, ofrece un singular espectáculo” ${ }^{6}$. En efecto, la discusión respecto a la causalidad/libertad se torna central a la hora de determinar cuáles son los mecanismos que permiten acreditar que un hecho en particular, el cual es contrario a la ley, fue causado libremente por un agente. Es decir, a la hora de imputar responsabilidad a un sujeto por una determinada acción u omisión. Lamentable es, empero, que pobre sea la injerencia que han tenido las discusiones filosóficas sobre esta materia en el mundo jurídico (por lo menos a nivel nacional), ya que ellas son una rica fuente de materia prima para elevar la discusión y traer a la mesa asuntos que la cada vez más común miopía interdisciplinaria no permiten aprehender.

Es lo anterior lo que nos motiva a intentar, en las páginas que siguen, iluminar la discusión de la imputación en el Derecho Penal, "sector en que la inquietud acerca de las razones de existencia arremete con una pujanza por completo inusitada en otras áreas del saber jurídico", a partir del desarrollo que Kant hace de la libertad trascendental en la Crítica de la Razón Pura. No nos dedicaremos, sin embargo, a realizar un extenso desarrollo de la libertad en Kant. En efecto, ello requeriría un exhaustivo estudio no solo de la libertad trascendental, sino que también de la libertad práctica ${ }^{8}$ (así como de las distintas lecturas que importantes filósofos le han dado a este asunto), lo que tornaría el presente trabajo en un interesante trabajo filosófico, pero de poca relevancia jurídica ${ }^{9}$. Lo que pretendemos aquí, en cambio, es hacer uso de algunas de las ideas de Kant para analizar una discusión penal que si bien no es actual, tiene injerencia en lo referente a la prueba del elemento subjetivo del delito.

Para ello seguiremos la siguiente estructura: Comenzaremos realizando una breve explicación del tratamiento que hace Kant de la libertad en la Crítica de la Razón Pura (I), para luego pasar a revisar, a grandes rasgos, las discusiones que en el Derecho Penal han surgido en lo que se refiere a la causalidad e imputabilidad (II). A continuación, desarrollaremos por qué resulta útil y atingente el tratar conjuntamente asuntos que a priori parecen tan disimiles (III) y luego terminaremos con un breve análisis de todo lo expuesto (IV).

\footnotetext{
6 José Luis Guzmán Dalbora, "Estudio preliminar", en La teoría de la libertad de la voluntad en la actual doctrina filosófica del derecho penal, de Karl Engisch (Valparaíso: Edeval, 2006), 15.

Guzmán Dalbora, "Estudio preliminar, 19.

8 Se ha de tener en consideración, no obstante, que como bien señala Heidegger "la libertad práctica encuentra su fundamento [is grounded] en la libertad trascendental". Martin Heidegger, The essence of human freedom: an introduction to philosophy, trad. Ted Sadler (London \& New York: Continuum, 2002), 18.

$9 \quad$ Esta aclaración es pertinente en atención a las observaciones recibidas.
} 


\section{LA LIBERTAD EN LA CRÍTICA DE LA RAZÓN PURA}

El problema de la posibilidad de una coexistencia entre la causalidad según leyes de la naturaleza y la libertad es tratado por Kant en la Dialéctica Trascendental en la sección dedicada a las Antinomias de la Razón Pura. Al igual que en las demás antinomias, la tercera, en la cual Kant trata la libertad, se presenta como un conflicto entre las ideas cosmológicas, es decir, entre las formas de concebir el mundo como un todo (como una totalidad de condiciones), en las que cada una de las posiciones (tesis y antítesis) son legítimas si se relativizan a un punto de vista ${ }^{10}$. En palabras sencillas, Kant señala que tanto el afirmar que existe la libertad como el negarla, es decir, el aseverar que el mundo se rige exclusivamente por la causalidad natural, se encuentra suficientemente fundado; no resulta posible el preferir una solución a la otra.

No debe, no obstante, creerse, dado que no puede optarse legítimamente por una opción en desmedro de la otra, que la dificultad para dilucidar el asunto reside en quien está haciendo el análisis. Por el contrario, el problema está, como bien señala el propio Kant, en que ambos bandos utilizan tesis pseudorracionales, ya que hacen uso de principios del entendimiento sin limitarse a aplicar la razón a los objetos de la experiencia, sino que los extienden más allá de sus límites.

Tales tesis < continúa diciéndonos Kant>, no necesitan ni esperar una confirmación empírica, ni temer una refutación. No sólo está cada una de ella libre en sí misma de toda contradicción, sino que encuentra las condiciones de su necesidad en la naturaleza de la razón misma. El problema reside, desgraciadamente, en que la tesis opuesta tiene en su favor unos fundamentos que gozan de la misma validez y necesidad ${ }^{11}$.

¿Qué hacer, entonces, ante tal trampa en la que nos han dejado las exploraciones kantianas en el océano de lo suprasensible? La opción más sensata, al igual que en la mayoría de los deportes, parecería ser el retirarse de la contienda y declarar un empate. En efecto, si no resulta evidente cual es el bando que merece la victoria, lo razonable es retirarse con la satisfacción de que por lo menos hubo una disputa digna de ser presenciada. Sin embargo, y tal como lo indica el académico de Königsberg en las primera líneas del prólogo a la primera

\footnotetext{
${ }^{10}$ Cf. Henry E Allison, "Kant on Freedom of the Will", Essays on Kant (Oxford, U.K.: Oxford University Press, 2012), 147-149.

${ }_{11}$ Kant, Crítica de la Razón Pura, B 449.
} 
edición de su primera Crítica, en estas materias "la razón humana tiene el destino singular [...] de hallarse acosada por cuestiones que no puede rechazar por ser planteadas por la misma naturaleza de la razón" (A VII); es decir, aun cuando no seamos capaces de proporcionar una repuesta satisfactoria a estas interrogantes, nuestra razón seguirá indagando y exigiendo que sus inquietudes sean resueltas. Ante tal panorama, Kant nos dice que,

$<$ no nos> queda otra alternativa <más $>$ que reflexionar sobre el origen de esta discordia de la razón consigo misma, con el fin de averiguar si tal discordia se debe a un simple malentendido. Podría ser que, una vez aclarado éste, desaparecieran las ufanas pretensiones de ambos bandos y que se iniciara, en su lugar, un tranquilo y duradero gobierno de la razón sobre el entendimiento y los sentidos (A 465, B 493).

Es decir, nuestra razón no debe aventurarse a esta disputa con la finalidad de declarar a uno de los dos contrincantes como vencedor, sino que más bien con el objetivo de encontrar aquello que produce una falta de dialéctica en la discusión y que genera que ésta se torne fútil ${ }^{12}$.

Ahora, ¿cómo se resuelve el conflicto entre la posibilidad de la coexistencia entre la causalidad natural y libertad? Bueno, como bien señala Heidegger, "la clave para resolver esta dificultad es la distinción entre fenómeno y cosa en sí, distinción que en si involucra el problema de la finitud del conocimiento"13. En efecto, ya en el prólogo a la segunda edición de la Crítica Kant adelanta esto al señalar que si se supone:

(...) que nuestro conocimiento empírico se rige por los objetos en cuanto cosas en sí, se descubre que lo incondicionado no puede pensare sin contradicción; por el contrario, suponiendo que nuestra representación de las cosas, tal como nos son dadas, no se rige por éstas en cuanto cosas en sí, sino que más bien esos objetos, en cuanto fenómenos, se rigen por nuestra forma de representación, desaparece la contradicción. Si esto es así y si, por consiguiente, se descubre que lo incondicionado no debe hallarse en las cosas en cuanto las conocemos (en cuanto nos son dadas) pero sí, en cambio, en las cosas en cuanto no las conocemos, en cuanto cosas en sí, entonces se pone de manifiesto que lo que al comienzo admitíamos a título de ensayo se halla justificado ${ }^{14}$.

El error, entonces, de quienes niegan la existencia de libertad reside en que sólo consideran en su análisis a los fenómenos, siendo así imposible para ellos concebir algo ajeno a

\footnotetext{
12 Esta manera de aproximarse a la problemática Kant lo llama método escéptico (A 424, B 451)

13 Martin Heidegger, The essence of human freedom: an introduction to philosophy, trad. Ted Sadler (London \& New York: Continuum, 2002), 163.

${ }_{14}$ Kant, Crítica de la Razón Pura, B XX-XXI
} 
las leyes de causalidad propias de la naturaleza; el de quienes aseveran que existe la libertad y a partir de dicha afirmación aseguran que es posible afirmar la existencia de un primer ente incausado (Dios) que produce toda otra causalidad, en cambio, en cosificar la libertad, es decir, es tratarla como fenómeno aplicándole las categorías de posibilidad de la experiencia.

En definitiva, la distinción entre fenómenos y cosas en sí crea un espacio lógico que posibilita que ambos bandos puedan estar en lo correcto: el determinista respecto a los objetos de la experiencia y el indeterminista respecto a objetos inteligibles ${ }^{15}$.

\section{CAUSALIDAD Y CULPABILIDAD: EL CASO DEL DERECHO PENAL}

Luego de realizar este breve recorrido por el tratamiento que Kant hace de la libertad trascendental en la Crítica de la Razón Pura, nos corresponde revisar, aunque de manera aún más breve, lo que se refiere a la causalidad y culpabilidad en el Derecho Penal.

En esta rama del derecho podemos encontrar (algo así como) un correlato de la distinción que Kant hace entre causalidad natural y libertad, en lo que se conoce como causalidad del delito y culpabilidad en el mismo. Lo primero se refiere a que, para condenar a un sujeto, necesariamente ha de haber una "vinculación entre la conducta del sujeto y el resultado previsto en el tipo legal"16, de manera que ha de ser posible el rastrear el origen de un hecho delictual al movimiento (o incluso a la ausencia de este) de un determinado sujeto; es decir, algo bastante similar a la causalidad natural del pensamiento kantiano. La culpabilidad, en cambio, se refiere a que para condenar a un sujeto no basta con que una acción delictiva sea consecuencia de la acción u omisión de un agente, sino que también se requiere que el sujeto haya tenido la intención de producir ese resultado delictivo a la hora de realizar aquella acción u omisión. Es decir, es necesario que sea posible el rastrear el origen de una cadena causal cuyo resultado es un hecho delictivo a la libertad de un sujeto. Así, no basta para castigar a una persona por el delito de homicidio que la muerte de la víctima se haya producido porque fue la bala de un arma que ella tenía en sus manos la que produjo su muerte, sino que se requiere también que esa persona haya querido, en su fuero interno, matar a la víctima. $\mathrm{Si}$, por ejemplo, quien disparó el arma que provocó la muerte de otra persona

5 Cf. Allison, "Kant on Freedom of the Will", 149.

16 Sergio Politoff Lifschitz, Jean Pierre Matus Acuña, y María Cecilia Ramírez G., Lecciones de derecho penal chileno: parte general (Editorial Jurídica de Chile, 2004), 174. 
lo hizo inintencionadamente, como sucedería en el caso que dicha persona estaba limpiando el arma y sin querer apretó el gatillo y la disparó, no sería (en principio) condenada por dicho delito $^{17}$. Ahora, dada la finalidad y extensión del presente trabajo, no nos adentraremos a revisar lo dicho por la doctrina acerca de la causalidad en los delitos, aun cuando ello podría ser de sumo interés. En cambio, nos detendremos en lo que se refiere a la culpabilidad y las discusiones que en dicho ámbito se han generado.

Si bien para muchos puede parecer un tanto añejo el asunto, la mayoría de las cátedras chilenas de Derecho Penal, a la hora de determinar el lugar de la culpa y el dolo (elemento subjetivo del delito) en la estructura del delito, centran la discusión en la disputa entre la teoría causalista y la finalista. La primera afirma que "la acción consiste en un puro movimiento corporal que causa una modificación del mundo exterior, perceptible por los sentidos"18 y que, por lo tanto, no hay ningún contenido intencional en la misma. Es decir, conciben la acción como un cierto movimiento que produce un cambio en el mundo fenoménico, pero ubican la voluntariedad o intención de dicho movimiento no en la acción misma, sino que en la culpabilidad. Siguiendo el ejemplo anterior, no sería posible verificar intencionalidad o siquiera negligencia en el hecho de que una persona dispare un arma y cause por ello la muerte de otra si se es causalista; lo único que se puede comprobar es que una persona disparó un arma y que otra murió. La intención o voluntariedad de dicha acción no es posible encontrarla en la acción misma, sino que ha de encontrarla el juez en otros elementos. El finalismo, en cambio, afirma que no es posible hablar de acción si se le quita a dicho concepto la intencionalidad que le es inherente. En efecto, esta teoría asevera que la manera de proceder del causalismo "es irreal e implica una división impracticable de lo que para la opinión común es una acción, sustrayéndole precisamente lo que en ella parece más característico: el propósito de alcanzar determinados objetivos" ${ }^{19}$. Sin embargo, entiende las razones que llevaron a proponerla y seguirla, ya que,

(...) la acción, concebida de este modo [causalista], tenía una consistencia física, era verificable empíricamente y se insertaba perfectamente en la cadena de los fenómenos causales con los cuales trabajaban las ciencias de la naturaleza. Por tales motivos, confería a la teoría del delito una aparente certeza estructural y desvinculaba su elemento fundamental de cuestiones "metafísicas" como la relativa a la libertad del comportamiento humano, que en el simple cambio del mundo exterior no tiene cabida ${ }^{20}$.

\footnotetext{
17 Digo "en principio" porque en caso de probarse que hubo negligencia por parte del hechor, eventualmente podría ser condenado por cuasi-delito de homicidio.

18 Enrique Cury Urzúa, Derecho penal: parte general (Santiago: Editorial Jurídica de Chile, 2005), 253.

Cury Urzúa, Derecho penal..., 253.

20 Cury Urzúa, Derecho penal..., 253.
} 
En efecto, y como bien señala Roxin, el causalismo responde al "pensamiento naturalista de finales siglo XIX, que intentaba reconducir todos los conceptos jurídicos a datos empíricos explicables por las ciencias naturales" ${ }^{21}$, por lo que es entendible que haya reducido el concepto de acción a lo empíricamente constatable.

El finalismo, en cambio, a partir de un análisis presuntamente fenomenológico ${ }^{22}$, viene a redefinir el concepto de acción restituyéndole el tan añorado elemento intencional que le había sido arrebatado por el causalismo bajo pretexto de cientificidad. Como bien señala Van Weezel, "el giro del finalismo consiste en asociar en forma automática a la ausencia o presencia de un cierto hecho psíquico una determinada consecuencia en el plano de la imputación penal" 23 . Es decir, a partir de él la acción pasa a tener un elemento psíquico que sirve de fundamento para imputar un hecho penalmente desvalorado al autor.

Si bien con este giro el finalismo pretendía superar el falso afán de cientificidad del causalismo, con él se inserta, como bien deja de manifiesto Cury en la cita antes enunciada, en una discusión sumamente compleja propia de la filosofía: el de la libertad.

\section{LÍMITES DE LO COGNOSCIBLE MEDIANTE LA RAZÓN ESPECULATIVA: UN INSUMO ÚTIL PARA LA CULPABILIDAD}

El breve desarrollo recién hecho deja de manifiesto que el núcleo de la discusión entre causalismo y finalismo se encuentra en la posibilidad o imposibilidad de comprobación empírica de la intención en la acción misma. En efecto, la primera teoría dice que no se ha de buscar el elemento subjetivo del delito en un fenómeno que consiste meramente en un movimiento corporal que produce un resultado, mientras que la segunda asevera que la intención se ha de buscar en la acción misma. Ahora, si bien esta discusión parece estar ya superada en la discusión jurídico-penal, estimamos que una revisión de la misma da cuenta de un problema actual: el de la acreditación en un proceso del elemento subjetivo del delito. En efecto,

${ }_{21}$ Claus Roxin, Derecho Penal: Parte General, trad. Diego-Manuel Luzón Peńa, Miguel Díaz y García Conlledo, y Javier de Vicente Remesal (Madrid: Civitas, 1997), 794.

22 En este sentido: Enrique Cury Urzúa, Derecho penal: parte general, 260.

23 Alex Van Weezel, "El dolo eventual como espacio de discrecionalidad", Doctrina y jurisprudencia penal 7 (2011): 29 . 
incluso autores contemporáneos como Roxin aseveran que la tarea actual del derecho penal consiste en "trabajar en el concepto mismo de culpabilidad y darle una configuración que lo libere de elementos irracionales y lo convierta en un baluarte empíricamente verificable de la limitación a la intervención propia del Estado de Derecho"24.

Ahora, si bien una aseveración como la de Roxin hace surgir una serie de interrogantes respecto a que se entiende en materia de culpabilidad como "empíricamente verificable" o si acaso la "racionalidad" propia de las ciencias exactas es un estándar que genera efectos positivos en el derecho ${ }^{25}$, estimamos pertinente, atendida la finalidad del presente trabajo, volver al al pensamiento kantiano.

Como bien se explicó en el apartado I, es la distinción entre fenómeno y cosa en sí lo que permite concebir de manera no contradictoria la coexistencia de la causalidad propia de la naturaleza con la libertad no determinada patológicamente. Sin embargo, esta afirmación hace surgir la siguiente interrogante: ¡significa la posibilidad lógica de esta coexistencia, entonces, que es posible que conozcamos mediante nuestra razón especulativa lo que la libertad trascendental es? ¿Acaso podemos tener conocimiento empírico de la libertad? Para responder a esta pregunta, atingente parece el revisar una reflexión que el filósofo de Königsberg hace en el apartado dedicado a El fundamento de la distinción de todos los objetos en general en fenómenos y númenos, donde señala que:

La analítica trascendental llega, pues, a este importante resultado: lo más que puede hacer a priori el entendimiento es anticipar la forma de una experiencia posible; nunca puede sobrepasar los límites de la sensibilidad —es en el terreno demarcado por esos límites donde se nos dan los objetos-, ya que aquellos que no es fenómeno no puede ser objeto de experiencia. (A 247)

En otras palabras, no es posible obtener un conocimiento empírico de lo suprasensible, ya que lo que único que podemos conocer a priori, esto es, las condiciones de posibilidad de la experiencia, sólo son aplicables a los datos sensibles y no a objetos que no son susceptibles de determinaciones espacio-temporales. La cosa en sí, entonces, aparece como un concepto límite que tiene por objetivo poner fin a las pretensiones de la sensibilidad (Cf. B 311).

Kant, por lo tanto, a través de su desarrollo en la tercera antinomia llega a la conclusión de que "naturaleza y causalidad por libertad no son incompatibles" (A 558, B 586), pero no afirma de ningún modo que los seres humanos seamos capaces de obtener conocimiento

\footnotetext{
Roxin, Derecho Penal..., 813.

25 Como bien seńala Gadamer, la pretensión de la ilustración de cientificidad por medio de la verificabilidad empírica de los fenómenos es un prejuicio más de la comprensión dentro de muchos otros. No mejor ni peor, sino que igual a los demás. Hans-Georg Gadamer, Truth and Method (London \& New York: Bloomsbury, 2013), 283.
} 
alguno acerca de la libertad considerada en sí o siquiera de cómo ésta opera. Pero, ¿qué tiene esto de relevante para la discusión entre causalismo y finalismo? ¿Acaso no se trata de dos temas completamente distintos cuya conexión, a lo más, es tangencial? En principio, esto puede parecer correcto (y en cierta medida lo es), pero nuestro objetivo no es el ver las influencias kantianas en las discusiones penales sobre la culpabilidad, sino tomar el método que Kant utiliza y las conclusiones a las que llega y aplicarlas a la discusión sobre la intencionalidad en los delitos.

Comencemos, entonces, por emplear el método escéptico a la discusión entre los finalistas y los causalistas prescindiendo, como jueces imparciales, de si los combatientes luchan por una buena o mala causa (Cf. B 451). Lo primero que aparece de manifiesto es que su disputa no versa sobre la posibilidad o imposibilidad de la libertad como independiente de la causalidad natural, como sucedía en la antinomia revisada. En cambio, ésta se refiere a si la intención de un sujeto que comete un delito (que necesariamente presupone que éste sea libre) se encuentra ya en la acción (u omisión) delictiva que realiza o en elementos distintos a ésta. Injustificada se encuentra, entonces, la afirmación de Cury antes descrita donde señala que sólo el finalismo se interna en las discusiones filosóficas sobre la libertad. En realidad, los causalistas también se ven inevitablemente arrastrados a dichas disputas, con la única diferencia que no se internan en ellas al momento de analizar la acción delictual, sino que en un momento ulterior. En suma, el método escéptico nos revela que su contienda no se ubica en sede filosófica, sino en asuntos relativos a la estructura del delito.

Ahora, si bien este enfoque nos ayudó a esclarecer que tanto el causalismo como el finalismo no se introducen en las discusiones filosóficas sobre libertad, sino que más bien la presuponen, también nos permite percatarnos de un asunto todavía más relevante, a saber, que ambas asumen que la causalidad por libertad, la cual encuentra su origen en un objeto inteligible, es comprobable por un juez mediante un procedimiento previamente establecido en la ley. Respecto al primer punto no parece haber problema; de hecho, el presuponer que los seres humanos somos libres y capaces de autodeterminarmos es algo necesario para que exista el derecho. En caso contrario, sólo se necesitarían máquinas con tecnología capaz de anticipar la causalidad natural que tendrá un resultado delictivo o ilegal para administrar justicia. El problema está, en cambio, en el segundo punto, ya que asume que es posible (y necesario) que un juez se introduzca en el mundo de lo suprasensible y establezca, más allá de toda duda razonable, que un sujeto tuvo la intención de cometer un delito y que ello lo llevó a dar inicio a una serie causal que tuvo como consecuencia un resultado delictivo. 
En otras palabras, no es que la discusión jurídica entre una posición indeterminista, en virtud de la cual "el hombre puede ser blanco de un reproche sólo porque él posee una suerte de soberanía, de superioridad o, precisamente, de «libertad» frente a sus tendencias y la situación respectiva, con sus seducciones al mal"26, y una determinista, que postule que "las causas del delito son siempre de dos clases diferentes: condiciones disposicionales y ambientales"27, sea inútil en un área como el derecho. Todo lo contrario, la especulación teórica es insumo fundamental para el saber jurídico (especialmente para el derecho penal). Lo que aquí postulamos, en cambio, es que los juristas, a la hora de entrar en discusiones que suponen inmiscuirse en problemas filosóficos, no deben olvidar una cuestión fundamental: que no somos dioses, sino que seres humanos. En efecto, los seres humanos no tenemos la capacidad de conocer objetos inteligibles (como lo es la libertad), por lo que es absurdo el exigir a los entes persecutores que acrediten los delitos y a los jueces que justifiquen sus sanciones basados en algo que jamás podremos conocer de manera directa. Es necesario, por lo tanto, que las pretensiones jurídicas sean más aterrizadas, no en el sentido de que se han de alejar de la especulación filosófica (que es como generalmente se entiende dicha frase), sino que, de hecho, todo lo contrario. Hace falta que los juristas estudien a profundidad los temas filosóficos a los que la discusión jurídica (en especial la del derecho penal) inevitablemente los lleva, para así no caer en cuestiones que dificultan la praxis y que pueden fácilmente ser evitadas si se está en compañía (aunque no exclusivamente) de autores como Kant.

En definitiva, esta lectura da cuenta de que la discusión entre causalistas y finalistas se ha mantenido absolutamente ajena a las discusiones filosóficas relevantes sobre el tema, ya que ambas les exigen a hombres comunes lo imposible, a saber, el conocimiento de un objeto que no es objeto de la intuición sensible (Cf. A 538, B 566) para poder condenar a un sujeto por la comisión de un delito: la libertad.

\footnotetext{
26 Karl Engisch, La teoría de la libertad de la voluntad en la actual doctrina filosófica del derecho penal, trad. José Luis Guzmán Dalbora (Valparaíso: Edeval, 2006), 76.

27 Engisch, La teoría..., 77.
} 


\section{CONCLUSIONES}

El método escéptico nos ha permitido dar cuenta de que la lucha entre causalistas y finalistas no estaba apuntando en la dirección correcta. En efecto, ambas teorías exigen que la causalidad por libertad sea acreditada en un proceso penal, pero ninguna se hace cargo de si ello es siquiera posible, o, en su defecto, de cómo ha de ser probada. Así, una y otra se han visto absolutamente desconectadas de la realidad empírica y han mantenido su incansable lucha en un campo de batalla "imaginado", por ponerlo de alguna manera, que es consecuencia de las inevitables pretensiones de la razón humana, pero motivada por la falta de conocimiento acerca de las investigaciones críticas de Kant.

No debe, empero, creerse que las conclusiones aquí vertidas tienen por objeto motivar un sistema de responsabilidad objetiva que se base exclusivamente en la causalidad natural. Por el contrario, su finalidad es alejar la discusión penal de las concepciones psicofísicas $^{28}$, como las describe Jakobs, que son las que hasta el minuto han sido las posiciones dominantes en esta área del derecho. Es decir, apartar la discusión penal del "océano ancho y borrascoso [...] donde algunas nieblas y algunos hielos que se deshacen prontamente producen la apariencia de nuevas tierras y engañan una y otra vez con vanas esperanzas al navegante ansioso de descubrimientos, llevándolo a aventuras que nunca es capaz de abandonar, pero que tampoco puede concluir jamás" (A 236, B 295), y atraerla hacia la isla de la verdad, como diría Kant.

Para terminar, es importante prevenir, como ya lo hacía el filósofo de Königsberg en 1787, que "la mencionada transformación sólo se refiere, pues, a las arrogantes pretensiones de las escuelas que quisieran seguir siendo en este terreno [...] los exclusivos conocedores y guardadores de unas verdades de las que no comunican a la gente más que el uso, reservando para sí la clave" (B XXXIII). Es decir, lo dicho en el presente trabajo no afectará en nada la praxis jurídica, ya que no es que a los jueces penales ante un caso en particular intenten penetrar en la psiquis del presunto delincuente para encontrar ahí el fundamento de su condena, sino que más bien deducen la culpabilidad del sujeto a partir de los indicios observables en el mundo fenoménico. La utilidad, entonces, se reduce meramente a ser una brújula doctrinaria que permita encontrar tierra firme a los juristas del derecho penal.

28 Cf. Günther Jakobs, Dogmática de Derecho penal y la configuración normativa de la sociedad (Madrid: Civitas, 2004), 116. 


\section{BIBLIOGRAFÍA}

Allison, Henry E. Idealism and Freedom: Essays on Kant's Theoretical and Practical Philosophy. Cambridge; New York: Cambridge University Press, 1996.

Allison, Henry E. "Kant on Freedom of the Will". En Essays on Kant, 137-61. Oxford, U.K.: Oxford University Press, 2012.

Cury Urzúa, Enrique. Derecho penal: parte general. Santiago: Editorial Jurídica de Chile, 2005.

Engisch, Karl. La teoría de la libertad de la voluntad en la actual doctrina filosófica del derecho penal. Traducido por José Luis Guzmán Dalbora. Valparaíso: Edeval, 2006.

Gadamer, Hans-Georg. Truth and Method. London \& New York: Bloomsbury, 2013.

Guzmán Dalbora, José Luis. "Estudio preliminar". En La teoría de la libertad de la voluntad en la actual doctrina filosófica del derecho penal, de Karl Engisch. Valparaíso: Edeval, 2006.

Harper, William L, y Ralf Meerbote. Kant on Causality, Freedom, and Objectivity. Minneapolis: University of Minnesota Press, 1984.

Heidegger, Martin. The essence of human freedom: an introduction to philosophy.

Jakobs, Günther. Dogmática de Derecho penal y la configuración normativa de la sociedad. Madrid: Civitas, 2004.

Kant, Immanuel. Crítica de la Razón Pura. Traducido por Pedro Ribas. Mexico D.F.: Taurus, 2013.

Politoff Lifschitz, Sergio, Jean Pierre Matus Acuña, y María Cecilia Ramírez G. Lecciones de derecho penal chileno: parte general. Editorial Jurídica de Chile, 2004.

Roxin, Claus. Derecho Penal: Parte General. Traducido por Diego-Manuel Luzón Peña, Miguel Díaz y García Conlledo, y Javier de Vicente Remesal. Madrid: Civitas, 1997.

Van Weezel, Alex. "El dolo eventual como espacio de discrecionalidad". Doctrina y jurisprudencia penal 7 (2011): 23-52. 